\title{
ANALISIS FAKTOR-FAKTOR YANG MEMPENGARUHI COMPETITIVENESS BERBASIS INDUSTRI KREATIF SUBSEKTOR KULINER PADA KAMPUNG UMKM KREATIF DI SURABAYA
}

\author{
Chintami Surya Ayu ${ }^{1)^{*}}$, Raya Sulistyowati ${ }^{1)}$ \\ 1) Fakultas Ekonomika dan Bisnis, Universitas Negeri Surabaya \\ Penulis Korespondensi: 1)* chintami.17080324020@mhs.unesa.ac.id, Rayasulistyowati@unesa.ac.id
}

\begin{abstract}
Abstrak
Permasalahan yang dialami oleh UMKM berbasis industri kreatif subsektor kuliner di Kampung UMKM Kreatif Putat Jaya adalah perkembangan pesat yang terjadi pada industri kuliner kreatif sehingga menimbulkan persaingan yang cukup kompetitif, kemunculan produk usaha kuliner berbasis industri kreatif dengan harga yang lebih terjangkau dan cita rasa produk yang lebih autentik, ketergantungan proses produksi pada jumlah permintaan sehingga tidak terdapat stok produksi, dan keterbatasan permodalan yang dimiliki oleh pelaku usaha, kurangnya kerjasama dengan pemasok dan sesama pelaku usaha kuliner kreatif, menyebabkan hanya beberapa UMKM saja yang menunjukkan perkembangan yang sangat baik. Tujuan penelitian ini adalah menganalisis dan menjelaskan faktor yang mempengaruhi competitiveness berbasis industri kreatif subsektor kuliner pada Kampung UMKM Kreatif yang terletak di Kelurahan Putat Jaya Kecamatan Sawahan Surabaya. Teknik pengambilan sample menggunakan sampel jenuh yang berjumlah 50 unit UMKM berbasis industri kreatif subsektor kuliner dijadikan sebagai sample penelitian. Dalam menganalisis data digunakan teknik analisis faktor melalui Kaiser-Mayer-Olkin KMO. Terdapat 3 faktor baru yang terbentuk yaitu faktor sumber ilmu pengetahuan dan teknologi dengan total variance senilai $44,059 \%$, faktor persaingan dengan total variance senilai $14,049 \%$ dan faktor sumber daya manusia dengan total variance senilai $10,22 \%$. Faktor sumber ilmu pengetahuan dan teknologi memiliki pengaruh paling kuat terhadap competitiveness industri kreatif subsektor kuliner di Kampung UMKM Kreatif Putat Jaya Surabaya.
\end{abstract}

Keywords: Competitiveness, Industri Kreatif Subsektor Kuliner, Analisis Faktor

Informasi Artikel:

Artikel Diterima: 7 Juni 2021

Artikel Direvisi: 17 Juni 2021

Artikel Disetujui: 21 Juni 2021 


\section{PENDAHULUAN}

Pandemi Covid-19 yang terjadi di dunia salah satunya yang juga dialami oleh Indonesia menyebabkan penurunan perekonomian sebesar 2,07\% pada Triwulan ke-IV 2020 (Badan Pusat Statistik, 2021). Hal tersebut juga berdampak pada sektor UMKM yang telah berkontribusi hingga $61,07 \%$ dalam pembentukan Produk Domestik Bruto Indonesia (KUKM， 2020:17). Dalam menangani krisis ekonomi yang terjadi selama pandemi covid-19 diperlukan pengembangan UMKM berbasis industri kreatif yang mengacu pada Intruksi Presiden Nomor 6 Tahun 2009 tentang pengembangan ekonomi kreatif dimana pengembangan kegiatan ekonomi di dasarkan pada kreativitas, ketrampilan dan bakat individu untuk menciptakan daya kreasi dan daya cipta individu yang bernilai ekonomis dan berpengaruh pada kesejahteraan masyarakat indonesia.

Salah satu pengembangan UMKM berbasis industri kreatif di Jawa Timur yaitu Kampung UMKM Kreatif yang berlokasi di Putat Jaya Surabaya. Dimana kawasan Putat Jaya dulunya merupakan kawasan lokalisasi yang dikenal dengan Lokalisasi Jarak yang akhirnya ditutup secara permanen pada tahun 2014. Pengembangan dan penelitian tentang UMKM di Kawasan Putat Jaya tersebut penting untuk dilakukan secara berkesinambungan untuk mencegah terjadinya kembali kegiatan prostitusi di lingkungan tersebut.
Subsektor unggulan di Kampung UMKM Kreatif Putat Jaya adalah kuliner dengan 50 unit UMKM yang aktif. Produk kuliner yang dijual di Kampung UMKM Kreatif Putat Jaya merupakan makanan dan minuman tradisional yang menggunakan ide kreatif pada proses pengolahan, resep maupun cara penyajiannya. Produk kuliner yang dijajakan berupa makanan dan minuman seperti bothok telur asin, rujak, rawon, soto, pecel, aneka jajanan pasar, keripik, sambel, olahan tempe, minuman jamu tradisional dan minuman herbal.

Permasalahan yang dialami oleh UMKM berbasis industri kreatif subsektor kuliner di Kampung UMKM Kreatif Putat Jaya adalah perkembangan pesat yang terjadi pada industri kuliner kreatif sehingga menimbulkan persaingan yang cukup kompetitif utamanya bagi usaha mikro, produk kuliner berbasis industri kreatif yang hadir dengan harga lebih murah dengan cita rasa produk lebih autentik, ketergantungan proses produksi pada jumlah permintaan sehingga tidak terdapat stok produksi, dan keterbatasan permodalan yang dimiliki oleh pelaku usaha, kurangnya kerjasama dengan pemasok dan sesama pelaku usaha kuliner kreatif, menyebabkan hanya beberapa UMKM saja yang menunjukkan perkembangan yang sangat baik. Banyaknya competitor kuliner kreatif yang berasal dari luar Kampung UMKM Kreatif Putat Jaya juga turut menjadi pesaing seperti Kampung Kue Rungkut Lor Surabaya, Kampung Tempe Sukomanunggal Surabaya, 
Kampung Kerupuk Gununganyar Surabaya dan Kampung Tempe yang berada di Tenggilis Mulya Surabaya. UMKM unggulan berbasis industri kreatif kuliner yang berada di Kampung UMKM Kreatif Putat Jaya harus selalu melakukan berbagai daya dan upaya agar dapat memenangkan persaingan. Hal tersebut disebabkan karena UMKM dengan jenis produk yang sama akan saling mengungguli dan menimbulkan persaingan yang semakin kompetitif (Nurhayati \& Khodijah, 2021:17).

Persaingan bisnis saat ini yang sangat ketat menjadi tantangan bagi para pelaku bisnis untuk tetap bertahan dalam persaingan tersebut (Artanti et al., 2019). Terdapat beberapa faktor yang dapat mempengaruhi competitiveness UMKM di Kampung UMKM Kreatif Putat Jaya diantaranya yaitu faktor kondisi. Pada UMKM berbasis industri kreatif kuliner di Kampung UMKM Kreatif Putat Jaya Surabaya, sumber daya manusia yang memiliki kreatifitas dalam mengolah atau menyajikan produk kuliner tradisional atau kuliner berbahan baku lokal dengan penampilan terbaru telah banyak bermunculan sehingga berpotensi meningkatkan persaingan antar UMKM.

Faktor kondisi permintaan juga merupakan faktor yang mempengaruhi posisi competitiveness (Porter, 1990). Dalam meningkatkan competitive advantage dan memperoleh pangsa pasar perusahaan perlu melakukan inovasi produk (Pratiwi dan Sulistyowati, 2020). Kondisi permintaan akan produk kuliner kreatif pada setiap UMKM yang berada di Kampung UMKM Kreatif Putat Jaya sangat menentukan jumlah produktivitas dari setiap UMKM.

Industri terkait dan pendukung termasuk faktor yang dapat mempengaruhi compettiveness suatu industri (Porter, 1990). Keunggulan bersaing dapat diciptakan melalui hubungan yang terjaga dengan baik pada rantai nilai produksi industri hulu dan industri hilir pada masing-masing industri kreatif kuliner di Kampung UMKM Kreatif Putat Jaya.

Strategi perusahaan, struktur dan persaingan merupakan faktor yang akan meningkatkan keberhasilan UMKM berbasis industri kreatif subsektor kuliner di Kampung UMKM Kreatif Putat Jaya Surabaya. Kondisi lingkungan bisnis yang berkembang pesat menuntut para pelaku UMKM agar menerapkan strategi yang sesuai agar bisnis dengan jenis yang sama dapat mempertahankan keunggulan bersaing berkelanjutan (Euis et al., 2019). Perkembangan dinamika competitiveness yang terjadi juga menuntut sebuah usaha untuk melakukan efektifitas strategi inovasi produk untuk mendapatkan kinerja bisnis yang diharapkan (Sulistyowati, 2021).

Penelitian ini dilakukan dalam rangka menganalisis faktor-faktor yang mempengaruhi competitiveness berbasis industri kreatif subsektor kuliner pada Kampung UMKM Kreatif di Putat Jaya Surabaya. Selain itu penelitian ini dilakukan 
juga bertujuan untuk mengetahui faktor inti yang paling berpengaruh secara dominan terhadap competitiveness industri kreatif subsektor kuliner di Kampung UMKM Kreatif Putat Jaya Surabaya sehingga industri kreatif di Kampung UMKM Kreatif Putat Jaya dapat mengetahui secara pasti faktor apa saja yang perlu ditingkatkan kembali untuk bisa bertahan di pasar dan memenangkan persaingan di era yang semakin competitive.

\section{TINJAUAN PUSTAKA}

\section{Competitive Advantage}

Competitive advantage mengacu pada posisi keunggulan perusahaan di pasar yang dapat menyebabkan perusahaan menjadi lebih baik dibandingkan dengan pesaingnya (Sukaatmadja et al., 2021). Competitive advantage merupakan tingkat dimana perusahaan dapat membangun posisi aman diatas para pesaingnya (Kankaew et al., 2021). Competitive advantage adalah sebuah posisi yang memiliki keunikan yang dikembangkan oleh sebuah organisasi dengan tujuan untuk mengalahkan pesaing (Porter, 1990). Dapat disimpulkan competitive advantage yaitu sebuah pengembangan posisi perusahaan untuk menempatkan perusahaan diatas para pesaingnya.

\section{Faktor-Faktor Yang Mempengaruhi Competitive Advantage}

Beberapa faktor yang berpengaruh terhadap competitive advantage suatu industri menurut Porter (2010) yaitu:

a. Faktor Kondisi
Faktor kondisi merupakan posisi faktor-faktor produksi, untuk bersaing dalam industri tertentu. Faktor kondisi meliputi beberapa hal diantaranya :

1. Sumber Daya Manusia

2. Sumber Daya Fisik / Alam

3. Sumber Ilmu Pengetahuan dan Ilmu Teknologi

4. Sumber Daya Modal

5. Sumber Daya Infrastruktur

b. Kondisi Permintaan

Kondisi permintaan dapat mempengaruhi Competitive advantage yang meliputi komposisi permintaan produk atau jasa dalam sebuah industri di suatu wilayah (Porter, 2008).

c. Industri Terkait dan Pendukung

Faktor industri terkait dan pendukung yaitu para pemasok dan industri lainnya yang saling berhubungan (Porter, 2008). Faktor yang berpengaruh dalam industri terkait dan pendukung meliputi beberapa hal diantaranya:

1. Keunggulan bersaing di industri pemasok

2. Keunggulan bersaing dalam industri terkait

d. Strategi, struktur perusahaan dan persaingan

Penentu keunggulan kompetitif dalam suatu industri adalah konteks dimana perusahaan diciptakan, dikelola dan dikembangkan pada kondisi persaingan yang ketat. Strategi 
perusahaan dan persaingan meliputi hal-hal dibawah ini yaitu :

1. Strategi dan Struktur Perusahaan

Keberhasilan industri yang diperoleh dari praktik manajemen yang terstruktur sesuai dengan kondisi lingkungan suatu industri tersebut didirikan. Sedangkan strategi merujuk pada kemampuan perusahaan dalam membuat produk yang dianggap unik untuk mencapai tujuan keberhasilan organisasi.

\section{Persaingan}

Suatu industri menjadi lebih unggul dari pesaing lainnya ketika melakukan inovasi produk yang merupakan unsur penting dalam mencapai keunggulan kompetitif.

\section{Competitiveness}

Competitiveness diartikan sebagai upaya dalam menyediakan produk atau jasa yang lebih efektif daripada pesaing dengan bantuan keunggulan kompetitif, pasar, manajemen organisasi dan manajemen proyek sehingga keuntungan dan pembangunan berkelanjutan dapat tercapai (Ni et al., 2021:).

Competitiveness dapat didefiniskan sebagai kontruksi multidimensi yang sebagian besar merupakan hasil dari interaksi antara sumber daya dan kemampuan (Lafuente et al., 2020 : 560). Pengertian lain tentang competitiveness adalah kemampuan untuk menciptakan produk dengan proses teknologi unik untuk menciptakan nilai tambah yang tinggi sesuai dengan kebutuhan pelanggan dengan biaya rendah, produktivitas tinggi untuk meningkatkan keuntungan (Porter, 2008).

Berikut ini indikator competitiveness (Porter, 2008) :

1) Harga Bersaing

Perusahaan harus mampu membuat produk yang sesuai dengan harga pasaran secara umum agar dapat meningkatkan competitiveness usahanya.

2) Kualitas

Kapabilitas suatu usaha memproduksi output yang disesuaikan dengan preferensi konsumen bahkan melebihi ekspektasi konsumen.

3) Keunggulan

Keunggulan usaha merupakan kemampuan suatu usaha dalam mengadirkan produk dengan biaya yang lebih rendah dibandingkan nilai manfaat yang akan didapatkan konsumen.

\section{Industri Kreatif Subsektor Kuliner}

Industri Kreatif Subsektor Kuliner sebagai kegiatan pengolahan, penyajian produk makanan dan minuman yang menekankan kreativitas, keindahan, budaya dan kearifan lokal (Kementerian Pariwisata dan Ekonomi Kreatif RI, 2014). Terdapat dua kategori utama kuliner yaitu jasa kuliner (foodservice) dan barang kuliner (specialty foods). Jasa kuliner dikategorikan menjadi dua jenis menurut aspek persiapan dan penyajiannya, dapat dibagi ke dalam dua kategori umum, yaitu restoran dan jasa boga. Sedangkan Barang kuliner adalah produk 
pangan olahan ataupun produk pangan dalam bentuk kemasan (BEKRAF, 2017).

\section{METODE PENELITIAN}

\section{Objek dan Waktu Penelitian}

Objek Penelitian ini yaitu UMKM berbasis industri kreatif subsektor kuliner yang terdapat di Kampung UMKM Kreatif Putat Jaya Kota Surabaya. Penelitian ini diselenggarakan pada bulan Maret hingga Mei tahun 2021.

\section{Populasi dan Sampel}

Pada peneitian ini menggunakan sampling jenuh dimana yang menjadi populasi adalah seluruh UMKM berbasis industri kreatif subsektor kuliner di Kampung UMKM Kreatif Putat Jaya Surabaya yang berjumlah 50 unit.

\section{Variabel yang Diteliti}

Berdasarkan teori faktor competitive advantage yang dikemukakan oleh (Porter, 2010) maka dalam penelitian ini indikator yang digunakan untuk menganalisis faktorfaktor competitivenees berbasis industri kreatif subsektor kuliner pada Kampung UMKM Kreatif di Surabaya adalah sebagai berikut :

1. Sumber daya manusia (X1)

2. Sumber Daya Fisik / Alam (X2)

3. Sumber Ilmu Pengetahuan dan Ilmu Teknologi (X3)

4. Sumber Daya Modal (X4)

5. Sumber Daya Infrastruktur (X5)

6. Komposisi permintaan (X6)

7. Keunggulan bersaing di industri pemasok (X7)

8. Keunggulan bersaing dalam industri terkait (X8)

9. Strategi dan struktur perusahaan (X9)

10. Persaingan (X10)

\section{Teknik Pengumpulan Data}

Metode pengumpulan data memanfaatkan teknik online quesionair menggunakan media googleform https://forms.gle/k15LXfxqVt5YAQaAA dan wawancara tidak terstruktur dengan responden. Skala pengukuran penelitian ini skala Likert dengan skor 5-1.

\section{Teknik Analisis Data}

Metode penelitian yang digunakan adalah kuantitatif. Pengujian terhadap instrumen penelitian dengan memanfaatkan uji validitas dan reliabilitas terhadap questioner. Teknik analisis data memanfaatkan analisis faktor. Analisis faktor dilakukan untuk mengetahui faktor-faktor yang dapat mengintrepertasikan korelasi atau hubungan indikator-indikator independen yang diteliti (Widarjono, 2020:189). Analisis faktor dilakukan dalam tiga tahap utama yaitu:

\section{Menghitung Korelasi antara indikator yang diteliti}

Persyaratan pada analisis faktor adalah kecukupan data. Teknik pengukuran kecukupan data menggunakan uji memanfaatkan Uji KMO (Kaiser-MayerOlkin) dengan bantuan SPSS 25 For Windows.

\section{Ekstraksi Faktor}

Ekstrasi faktor (extraction) merupakan 
langkah yang dilakukan untuk mereduksi data dari beberapa indikator guna menghasilkan faktor yang lebih sedikit yang mampu mengintrepretasikan korelasi antara indikator yang diobservasi. Principal Component Analysis merupakan metode yang digunakan untuk mengekstraksi faktor dalam penelitian ini.

\section{Rotasi Faktor}

Metode rotasi faktor yang digunakan dalam penelitian ini adalah varimax method yaitu metode rotasi orthogonal untuk meminimalisasi jumlah indikator yang mempunyai factor loading tinggi pada tiap faktor.

\section{HASIL DAN PEMBAHASAN}

Hasil pengujian terhadap instrument terhadap 10 indikator dengan 43 item pertanyaan yang digunakan dalam angket dan setelah dilakukan pengujian validitas dengan nilai $\mathrm{R}$ tabel lebih dari 0,312 . Hal tersebut mengindikasikan bahwa seluruh instrument dinyatakan valid. Setelah itu berdasarkan hasil uji reliabilitas melalui software SPSS 25 dengan menghitung nilai Cronbach Alpha, seluruh indikator mempunyai nilai Cronbach Alpha sebesar 0,902. Nilai tersebut melebihi angka 0,60 maka dapat dinyatakan bahwa seluruh item indikator adalah reliabel dan layak untuk dimanfaatkan dalam penghimpunan data. Berdasarkan data yang terhimpun, karakteristik responden yaitu diketahui responden dengan lama usaha 1 s.d 3 tahun sebanyak 2 orang atau 4\%, 3 s.d 5 tahun sebanyak 15 orang atau 30\%, >5 tahun sebanyak 33 orang atau $66 \%$.

Berdasarkan jumlah tenaga kerja yang dimiliki diketahui bahwa UMKM dengan jumlah tenaga kerja sebanyak 1 orang yaitu 21 UMKM atau $42 \%$ sedangkan 29 UMKM lainnya memiliki tenaga kerja sebanyak 2-3 orang atau $58 \%$.

Dilihat dari sumber permodalan yang digunakan yaitu sebanyak 22 UMKM atau $44 \%$ menggunakan modal campuran 1 dengan kombinasi antara tabungan pribadi dan Kredit Usaha Rakyat, 4 UMKM atau $8 \%$ menggunakan modal campuran 2 yang terdiri dari Tabungan Pribadi, Dana Pinjaman Mitra BUMN (PT Telkom, PT. Perkebunan Nusantara), 24 atau $48 \%$ UMKM menggunakan modal campuran 3 yang terdiri dari gabungan antara tabungan pribadi, Kredit Usaha Rakyat dan Dana Pinjaman Mitra BUMN ((PT Telkom, PT. Perkebunan Nusantara).

\section{Hasil Analisis Data}

\section{Menghitung Korelasi Indikator yang Diobservasi}

a) Kaiser-Meyer Olkin (KMO)

Pengukuran kecukupan sampling setiap indikator secara menyeluruh dapat dilakukan dengan metode KMO. Berikut ini tabel pengujian KMO: 
Tabel 1 KMO and Bartlett's Test

\begin{tabular}{llr}
\hline $\begin{array}{l}\text { Kaiser- } \\
\text { Meyer-Olkin }\end{array}$ & 0,805 \\
$\begin{array}{l}\text { Measure of } \\
\text { Sampling }\end{array}$ & & \\
Adequacy. & & \\
\hline $\begin{array}{l}\text { Bartlett's Test } \\
\text { of Sphericity }\end{array}$ & $\begin{array}{l}\text { Approx. Chi- } \\
\text { Square }\end{array}$ & 205,640 \\
\hline & Df & 45 \\
\hline & Sig. & 0 \\
\hline
\end{tabular}

Sumber : Diolah peneliti, 2021

Berdasarkan tabel KMO and Bartlett's Test diperoleh hasil pengujian Kaiser-MeyerOlkin Measure of Sampling Adequacy adalah 0,805 . Artinya metode analisis faktor sudah tepat dan dapat dipertanggungjawabkan. Hal ini dikarenakan nilai Kaiser-Meyer-Olkin $>0,5$. Lalu dapat dilihat dari nilai signifikasi yaitu 0,000 yang mana hasil tersebut $<0,05$ dapat disimpulkan bahwa analisis tersebut tepat.

Selanjutnya adalah dengan melihat nilai Anti Image Matrix pada kolom Anti image Correlation. Berikut adalah hasil Nilai Measure of Sampling Adequancy (MSA):

Tabel 2 Measure of Sampling Adequancy (MSA)

\begin{tabular}{cc}
\hline Keterangan & $\begin{array}{c}\text { Nilai Measure of Sampling } \\
\text { Adequancy }(\text { MSA })\end{array}$ \\
\hline X1 & 0,675 \\
\hline X2 & 0,792 \\
\hline X3 & 0,835 \\
\hline X4 & 0,843 \\
\hline X5 & 0,782 \\
\hline X6 & 0,830 \\
\hline X7 & 0,783 \\
\hline X8 & 0,876 \\
\hline X9 & 0,855 \\
\hline X10 & 0,550 \\
\hline
\end{tabular}

Sumber : Diolah Peneliti, 2021
Berdasarkan tabel diatas menunjukkan nilai Measure of Sampling Adequancy (MSA) memiliki nilai $>0,5$. Sehingga indikator tersebut dapat dilanjutkan menuju analisis berikutnya.

\section{Ekstraksi Faktor}

Dalam mereduksi data dari setiap indikator maka dilakukan ekstraksi faktor guna menghasilkan faktor yang lebih kecil sehungga dapat merepresentasikan korelasi setiap indikator yang diteliti. Adapaun hasil Principal Component Analysis sebagai berikut:

\section{Tabel 3 Total Variance Explained}

\begin{tabular}{ccll}
\hline Component & \multicolumn{3}{c}{ Initial Eigenvalues } \\
\cline { 2 - 4 } & Total & $\begin{array}{c}\text { \% of } \\
\text { Variance }\end{array}$ & $\begin{array}{c}\text { Cumu } \\
\text { lative \% }\end{array}$ \\
\hline 1 & 4.406 & 44.059 & 44.059 \\
\hline 2 & 1.405 & 14.049 & 58.108 \\
\hline 3 & 1.022 & 10.220 & 68.329 \\
\hline
\end{tabular}

Extraction Method: Principal Component Analysis.

Sumber: Output SPSS 25

Tabel output total variance explainied pada bagian "initial eigenvalues" terdapat 3 faktor baru yang berhasil tercipta dari 10 indikator sebelumnya yang dianalisis. Persyaratan yang harus terpenuhi untuk membentuk sebuah faktor ialah component eigentvalue $>1$. Component 1 nilainya 4,406 >1 dapat dijadikan sebagai faktor 1 yang dapat merepresentasikan 44,059 variasi. Sedangkan component 2 nilai eigenvalues mencapai 1.405 atau >1 menjadi faktor 2 dan dapat merepresentasikan $14.049 \%$ variasi. nilai eigenvalues component 3 yaitu 1,022 mampu menjelaskan $10,220 \%$ variasi. 


\section{Rotasi Faktor}

Dalam memudahkan proses pengintrepretasian struktur faktor yang lebih sederhana dibutuhkan rotasi faktor. Metode rotasi faktor menggunakan varimax method yaitu metode rotasi orthogonal untuk memperkecil total indikator dengan factor loading tinggi pada setiap faktor.

Tabel 4 Rotated Component Matrix

\begin{tabular}{llll}
\hline & \multicolumn{3}{c}{ Component } \\
\hline & 1 & 2 & 3 \\
\hline $\begin{array}{l}\text { Sumber daya } \\
\text { manusia (X1) }\end{array}$ & 0.056 & 0.199 & 0.882 \\
\hline $\begin{array}{l}\text { Sumber Daya } \\
\text { Fisik/Alam (X2) }\end{array}$ & 0.679 & 0.355 & 0.363 \\
\hline
\end{tabular}

\begin{tabular}{lllll}
\hline Sumber & Ilmu & 0.864 & -0.024 & 0.062
\end{tabular}

Pengetahuan

Dan Ilmu

Teknologi (X3)

\begin{tabular}{lllll}
\hline Sumber & daya & 0.767 & -0.089 & 0.147
\end{tabular}

modal (X4)

\begin{tabular}{lllll}
\hline Sumber & daya & 0.719 & 0.432 & 0.049
\end{tabular} infrastruktur

(X5)

\begin{tabular}{llll}
\hline $\begin{array}{l}\text { Komposisi } \\
\text { permintaan (X6) }\end{array}$ & 0.684 & -0.131 & 0.500 \\
\hline $\begin{array}{l}\text { Keunggulan di } \\
\text { bersaing di } \\
\text { industri } \\
\text { pemasok (X7) }\end{array}$ & 0.815 & 0.259 & -0.032 \\
\hline $\begin{array}{l}\text { Keunggulan } \\
\text { bersaing dalam } \\
\text { industri terkait } \\
(X 8)\end{array}$ & 0.526 & 0.444 & -0.169 \\
\hline $\begin{array}{l}\text { Strategi dan } \\
\text { struktur } \\
\text { perusahaan (X9) }\end{array}$ & 0.321 & 0.678 & 0.142 \\
\hline $\begin{array}{l}\text { Persaingan } \\
\text { (X10) }\end{array}$ & -0.179 & 0.787 & 0.126 \\
\hline
\end{tabular}

\section{Sumber: Output SPSS 25}

Berdasarkan tabel 4 diatas maka dapat diinterpretasikan bahwa terdapat 3 faktor inti signifikan untuk dikelompokkan. Kelompok faktor-faktor tersebut dilakukan dengan mengamati factor loading dengan nilai tertinggi dari 3 kelompok faktor tersebut.

Pengelompokan faktor-faktor tersebut dapat diketahui dalam tabel berikut:

Tabel 5 Nilai Rotasi Faktor

\begin{tabular}{|c|c|c|c|c|}
\hline $\begin{array}{c}\text { Fak } \\
\text { tor }\end{array}$ & Variabel & $\begin{array}{c}\text { Load } \\
\text { ing }\end{array}$ & $\begin{array}{c}\% \text { of } \\
\text { Varian } \\
\text { ce }\end{array}$ & $\begin{array}{l}\text { Cummu } \\
\text { lative \% }\end{array}$ \\
\hline \multirow[t]{8}{*}{ I } & $\begin{array}{l}\text { Sumber } \\
\text { Daya } \\
\text { Fisik/Alam } \\
\text { (X2) }\end{array}$ & 0,679 & 44,059 & 44,059 \\
\hline & $\begin{array}{l}\text { Sumber Ilmu } \\
\text { Pengetahuan }\end{array}$ & 0,864 & & \\
\hline & $\begin{array}{l}\text { Dan Ilmu } \\
\text { Teknologi } \\
\text { (X3) }\end{array}$ & & & \\
\hline & $\begin{array}{l}\text { Sumber daya } \\
\text { modal (X4) }\end{array}$ & 0,767 & & \\
\hline & $\begin{array}{l}\text { Sumber daya } \\
\text { infrastruktur } \\
\text { (X5) }\end{array}$ & 0,719 & & \\
\hline & $\begin{array}{l}\text { Komposisi } \\
\text { permintaan } \\
\text { (X6) }\end{array}$ & 0,684 & & \\
\hline & $\begin{array}{l}\text { Keunggulan } \\
\text { bersaing di } \\
\text { industri } \\
\text { pemasok } \\
\text { (X7) }\end{array}$ & 0,815 & & \\
\hline & $\begin{array}{l}\text { Keunggulan } \\
\text { bersaing } \\
\text { dalam } \\
\text { industri } \\
\text { terkait (X8) }\end{array}$ & 0,526 & & \\
\hline \multirow[t]{2}{*}{ II } & $\begin{array}{l}\text { Strategi dan } \\
\text { struktur } \\
\text { perusahaan } \\
\text { (X9) }\end{array}$ & 0,678 & 14,049 & 58,108 \\
\hline & $\begin{array}{l}\text { Persaingan } \\
\text { (X10) }\end{array}$ & 0,787 & & \\
\hline III & $\begin{array}{l}\text { Sumber } \\
\text { Daya } \\
\text { Manusia } \\
\text { (X1) }\end{array}$ & 0.882 & 10,220 & 68,329 \\
\hline
\end{tabular}


Menurut tabel 5 diatas terdapat 3 faktor baru yang terbentuk setelah dilakukan rotasi faktor. Faktor pertama terdiri dari sumber daya fisik/alam (X2), sumber ilmu pengetahuan dan ilmu teknologi (X3), sumber daya modal (X4), sumber daya infrastruktur (X5), komposisi permintaan (X6), Keunggulan bersaing di industri pemasok (X7), Keunggulan bersaing dalam industri terkait (X8). Faktor kedua terdiri dari Strategi dan struktur perusahaan (X9) dan persaingan (X10). Faktor ketiga terdiri dari sumber daya manusia (X1).

Berikut ini pemaparan 3 faktor baru yang berhasil terbentuk:

\section{Faktor Sumber Ilmu Pengetahuan dan Teknologi}

Kelompok faktor ini diberi nama dengan variabel yang memiliki nilai loading tertinggi yaitu Faktor Sumber Ilmu Pengetahuan dan Teknologi dengan nilai loading factor 0,864. Faktor ini mempunyai pengaruh pada competitiveness UMKM berbasis industri kreatif sub sektor kuliner di Kampung UMKM Kreatif Putat Jaya Surabaya dengan total variance tertinggi yaitu sebesar 44,059\%. Hal tersebut sesuai dengan hasil penelitian yang dilakukan Falciola et al (2020) bahwa faktor sumber ilmu pengetahuan dan teknologi berpengaruh secara positif dan signifikan terhadap competitiveness pada perusahaan. Sehingga dengan keterbaruan sumber ilmu pengetahuan dan perkembangan teknologi yang diterapkan dapat membantu suatu usaha dalam mengetahui informasi tentang selera pasar yang dinamis untuk meningkatkan competitiveness usahanya. Hal tersebut juga didukung oleh penelitian Raf (2011) yang menyatakan Ilmu Pengetahuan dan Teknologi (IPTEK) berpengaruh terhadap peningkatan competitiveness.

Berdasarkan hasil analisis data variabel yang mendukung kelompok faktor sumber ilmu pengetahuan dan teknologi yaitu sumber daya fisik/alam (X2), sumber ilmu pengetahuan dan ilmu teknologi (X3), sumber daya modal (X4), sumber daya infrastruktur (X5), komposisi permintaan (X6), keunggulan bersaing di industri pemasok (X7), keunggulan bersaing dalam industri terkait (X8).

Sumber ilmu pengetahuan berupa pengetahuan dasar di bidang industri kuliner diperoleh dari berbagai sumber seperti pengetahuan yang berasal dari Asosiasi Pengusaha Industri Kecil Menengah Indonesia (APIKMI) Surabaya dalam memfasilitasi UMKM untuk mendapatkan informasi tentang selera pasar. Selain itu terdapat lembaga yang terlibat aktif dalam memberikan pengetahuan adalah perguruan tinggi. Perguruan tinggi sebagai lembaga akademis berperan dalam memberikan pengetahuan tentang proses produksi melalui pelatihan berbasis industri kreatif sehingga mampu meningkatkan competitiveness berbasis industri kreatif di Kampung UMKM Kreatif Putat Jaya Surabaya. 


\section{Faktor Persaingan}

Pada kelompok faktor ini yang memiliki nilai factor loading tertinggi yaitu faktor persaingan dengan nilai 0,787. Variabel yang mendukung kelompok faktor persaingan yaitu variabel Strategi dan struktur perusahaan (X9) dan variabel persaingan (X10). Faktor persaingan mempengaruhi competitiveness UMKM berbasis industri kreatif sub sektor kuliner di Kampung UMKM Kreatif Putat Jaya Surabaya dengan total variance sebesar 14,049\%. Hal tersebut selaras dengan penelitian Suhartini dan Evie (2013) yang menyebutkan bahwa struktur perusahaan strategi dan persaingan berpengaruh terhadap competitiveness usaha. Faktor persaingan yang mempengaruhi competitiveness industri kreatif subsektor kuliner di Kampung UMKM Kreatif Putat Jaya Surabaya dipengaruhi oleh strategi dan struktur usaha dan persaingan yang ketat antar sesama pelaku usaha. Hal tersebut juga mendukung hasil penelitian yang dilakukan oleh Handayani et al., (2012) yang menyatakan bahwa strategi usaha berpengaruh positif terhadap competitiveness usaha.

UMKM berbasis industri kreatif subsektor kuliner yang terdapat di Kampung UMKM Kreatif Putat Jaya Surabaya menerapkan strategi usaha dengan cara menghasilkan suatu produk unik yang berbeda dengan pesaing dan meciptakan produk kuliner yang bervariasi. Struktur usaha juga dapat mempengaruhi competitiveness UMKM industri kreatif kuliner dengan melakukan manajemen yang disesuaikan dengan kondisi lingkungan

dapat

meningkatkan competitiveness.

\section{Faktor Sumber Daya Manusia}

Pada kelompok faktor ini diberi nama dengan faktor sumber daya manusia yang menjadi satu-satunya variabel yang membentuk kelompok faktor sumber daya manusia dengan nilai factor loading sebesar 0,882. Sumber Daya Manusia sebagai satusatunya variabel pembentuk faktor sumber daya manusia yang mempengaruhi competitiveness UMKM berbasis industri kreatif sub sektor kuliner di Kampung UMKM Kreatif Putat Jaya Surabaya dengan total variance sebesar $10,22 \%$. Hal tersebut mendukung hasil penelitian (Euis et al., 2019) yang terbukti bahwa sumber daya manusia berpengaruh secara positif terhadap competitiveness.

Sumber daya manusia berperan penting dalam mempengaruhi competitiveness suatu industri dalam hal ketersediaan jumlah pekerja yang memadai dan keahlian tenaga kerja. Industri kreatif subsektor kuliner yang berada di Kampung UMKM Kreatif Putat Jaya Surabaya secara aktif mengikuti pelatihan seperti pelatihan teknologi tepat guna, pelatihan digital marketing dan juga pelatihan desain produk untuk meningkatkan keahlian tenaga kerja sehingga mampu mendorong competitiveness berbasis industri kreatif subsektor kuliner. 


\section{KESIMPULAN DAN SARAN}

Dapat ditarik kesimpulan tentang faktor yang mempengaruhi competitiveness berbasis industri kreatif subsektor kuliner di Kampung UMKM Kreatif Putat Jaya Surabaya dapat disimpulkan bahwa terdapat 10 faktor berpengaruh terhadap competitiveness industri kreatif subsektor kuliner di Kampung UMKM Kreatif Putat Jaya Surabaya yaitu faktor sumber daya manusia, faktor sumber daya fisik / alam, faktor sumber ilmu pengetahuan dan ilmu teknologi, faktor sumber daya modal, faktor sumber daya infrastruktur, faktor komposisi permintaan, faktor keunggulan bersaing dalam industri terkait, faktor strategi dan struktur perusahaan serta faktor persaingan.

Setelah dilakukan penelitian menggunakan teknik analisis faktor maka terdapat 3 faktor baru yang terbentuk dalam mempengaruhi competitiveness industri kreatif subsektor kuliner di Kampung UMKM Kreatif Putat Jaya Surabaya yaitu faktor sumber ilmu pengetahuan dan teknologi dengan total variance senilai $44,059 \%$, faktor persaingan dengan total variance senilai $14,049 \%$. dan faktor sumber daya manusia dengan total variance senilai $10,22 \%$.

Dari ketiga faktor baru yang terbentuk diperoleh hasil bahwa faktor sumber ilmu pengetahuan dan teknologi memiliki pengaruh paling kuat terhadap competitiveness industri kreatif subsektor kuliner di Kampung UMKM Kreatif Putat Jaya Surabaya dengan total variance tertinggi yaitu sebesar 44,059\%.

\section{SARAN}

Berdasarkan hasil penelitian yang telah dipaparkan maka penelitian berikutnya diharapkan dapat mengembangkan faktor lain yang tidak diteliti pada penelitian ini. Hasil penelitian diketahui bahwa variabel sumber ilmu pengetahuan dan teknologi memiliki hubungan yang paling kuat. Oleh sebab itu, UMKM berbasis indstri kreatif subsektor kuliner yang terdapat di Kampung UMKM Kreatif Putat Jaya Surabaya disarankan untuk selalu mempelajari ilmu pengetahuan dan teknologi yang terbaru agar senantiasa berkembang serta dapat mengoptimalkan competitiveness usahanya dan memenangkan persaingan.

\section{REFERENSI}

Artanti, Y., Hari Prasetyo, F., \& Sulistyowati, R. (2019). How Social Media Marketing Influences Online Purchasing Decision: Study of the Viral Marketing and Perceived Ease of Use. KnE Social Sciences, 3(11), 988. https://doi.org/10.18502/kss.v3i11.4066 Ayu Pratiwi, W., \& Sulistyowati, R. (2020). Pengaruh Inovasi Produk Dan Social Media Marketing Terhadap Sales Performance Pada Ikm Batik Gedog Kabupaten Tuban. Jurnal Pendidikan Tata Niaga (JPTN), 8(1), 681-687.

Badan Pusat Statistik. (2021). Statistik Pertumbuhan Ekonomi Indonesia Triwulan IV-2020 (Issue 13).

Euis, Purnomo, D., \& Akhmad, J. (2019). 
Analisis Faktor-Faktor Yang Mempengaruhi Di Perkampungan Industri Kecil ( PIK ). 8(2).

Falciola, J., Jansen, M., \& Rollo, V. (2020). Defining firm competitiveness: A multidimensional framework. World Development, $\quad 129, \quad 104857$. https://doi.org/10.1016/j.worlddev.2019 .104857

Handayani, N. U., Santoso, H., \& Pratama, I. (2012). Faktor-Faktor YANG memengaruhi Peningkatan Daya Saing Klaster Mebel di Kabupaten Jepara. Jurnal Teknik Industri, 13, 22-30.

Kankaew, K., Yapanto, L. M., Waramontri, R., Arief, S., Hamsir, H., Sastrawati, N., \& Espinoza-Maguiña, M. R. (2021). Supply chain management and logistic presentation: Mediation effect of competitive advantage. Uncertain Supply Chain Management, 9(2), 255264.

https://doi.org/10.5267/j.uscm.2021.3.0 07

KUKM, K. I. (2020). Rencana strategis kementerian koperasi dan usaha kecil dan menengah tahun 2020 - 2024.

Lafuente, E., Szerb, L., \& Rideg, A. (2020). A system dynamics approach for assessing SMEs' competitiveness. Journal of Small Business and Enterprise Development, 27(4), 560. https://doi.org/10.1108/JSBED-062019-0204

Ni, G., Xu, H., Cui, Q., Qiao, Y., Zhang, Z., Li,
H., \& Hickey, P. J. (2021). Influence mechanism of organizational flexibility on enterprise competitiveness: The mediating role of organizational innovation. Sustainability (Switzerland), 13(1), 1-23. https://doi.org/10.3390/su13010176

Nurhayati, D., \& Khodijah, S. (2021). Analisis Faktor-Faktor yang Mempengaruhi Daya Saingusaha Mikro , Kecil dan Menengah ( UMKM ) Batik Pasuruan. $10,16-23$.

Porter, M. E. (1990). Competitive Advantage Of Nations (1st ed.). Free Press.

Porter, M. E. (2008). On Competition. Harvard Business School Publishing.

Porter, M. E. (2010). Strategi Bersaing Terjemahan Sigit Suryanto. Kharisma Publishing Group.

Raf, M. (2011). Analisis Eksplanatori Faktor Daya Saing Industri Kecil (Studi Pada Sentra Industri Kecil Batik Di Kota Jambi). Jurnal Manajemen Dan Kewirausahaan, 14(2). https://doi.org/10.9744/jmk.14.2.91101

Suhartini, \& Evie, Y. (2013). Faktor-Faktor Yang Mempengaruhi Analisis Daya Saing Industribatik Berbasis Diamond Porter Modelling. Prosiding Seminar Nasional Multi Disiplin Ilmu\&Call For Papersunisbank (Sendi_U, 978-979.

Sukaatmadja, I. P. G., Yasa, N. N. K., Rahyuda, H., Setini, M., \& Dharmanegara, I. B. A. (2021). Competitive advantage to 
p-ISSN : 2301-7775

e-ISSN : 2579-8014

NIAGAWAN Vol 10 No 2 Juli 2021

enhance internationalization and marketing performance woodcraft industry: A perspective of resourcebased view theory. Journal of Project Management, $\quad 6, \quad 45-56$. https://doi.org/10.5267/j.jpm.2020.9.00 2

Sulistyowati, R. (2021). Does Impact of Entrepreneurial Literacy and Digital
Literacy on a Businessmen Who Influences the Strategy to Maintain SME in The Pandemic Era? Technium Social Sciences Journal, 18, 84. file://C:/Users/User/AppData/Local/Te mp/2971-Article Text-11811-1-1020210407.pdf

Widarjono, A. (2020). Analisis Multivariat Terapan (2nd ed.). UPP STIM YKPN. 